\title{
Ideal stope profile to manage seismicity in deep tabular narrow reef mines
}

\author{
O. Rakumakoe
}

AngloGold Ashanti, South Africa

\begin{abstract}
More regional stability pillars have been introduced in deep narrow reef mining stope designs with an aim of increasing the loading area and reducing the induced stress on the active mining stope faces creating a stiffer loading system. Mponeng mine introduced strike pillars into the conventional sequential grid mining layout in 2014 further reduce an already low extraction ratio. This resulted in a reduction in the overall seismic potency two years later, however, the seismic potency/production graphs remained erratic month on month. Cycle mining practice introduced in 2016 was observed to enable compliance to the inter-panel lead-lag standard however did not reduce the erratic seismic response. Studies into the sources of seismic events has indicated that shear fracturing ahead of the stope face is one of the main seismic sources in deep gold mines. In this paper we illustrate that by establishing an ideal stope profile to manage the formation of the shear fractures, a much more consistent seismic potency/production graph can be achieved.
\end{abstract}

\section{INTRODUCTION}

Ultra-deep mining is characterized by the high stress levels and the associated intensive rock mass fracturing and the resultant seismic activity. Over the past decades the mining industry has studied and refined mining methods to manage stress levels with the increasing mining depth. A good example was the introduction of the sequential grid mining method to improve on the once successful long wall mining. These changes have resulted in significant improvements in reducing rock related (falls of ground and rock bursts) incidents and accidents.

Most of the developments in ultra-deep mining methods were aimed at managing the high stope face stress levels and preventing slip on geological structures. The latter has been successfully managed by incorporating bracket pillars against the structures. Management the face stresses is achieved by limiting the mining spans to create a stiffer stope layout on a regional scale and therefore limiting the energy release rate (ERR), Ryder and Jager (2002). Some of remaining mining induced stress and strain energy is then further managed by the designing and implementation of a suitable stope profile. A stope profile refers to the layout of panels to form a stope and is determined be the panel length, the panel orientation and the inter-panel lead-lag used within the stope configuration.

The stope profile plays a role in the loading on the rock mass ahead of the stope and the subsequent fracturing. The work presented in this paper illustrates the effects of stope configuration on seismic activity associated with an advancing stope and how establishing an ideal stope configuration can improve the seismic response. 


\section{BACKGROUND}

To ensure safe production at ultra-depth, AngloGold Ashanti's Mponeng mine has continuously looked to improve the mine design and mining methods. Currently the world's deepest mine, Mponeng is located $76 \mathrm{~km}$ south west of Johannesburg (See Figure 1) with mining taking place at a depth of $3550 \mathrm{~m}$ below surface.

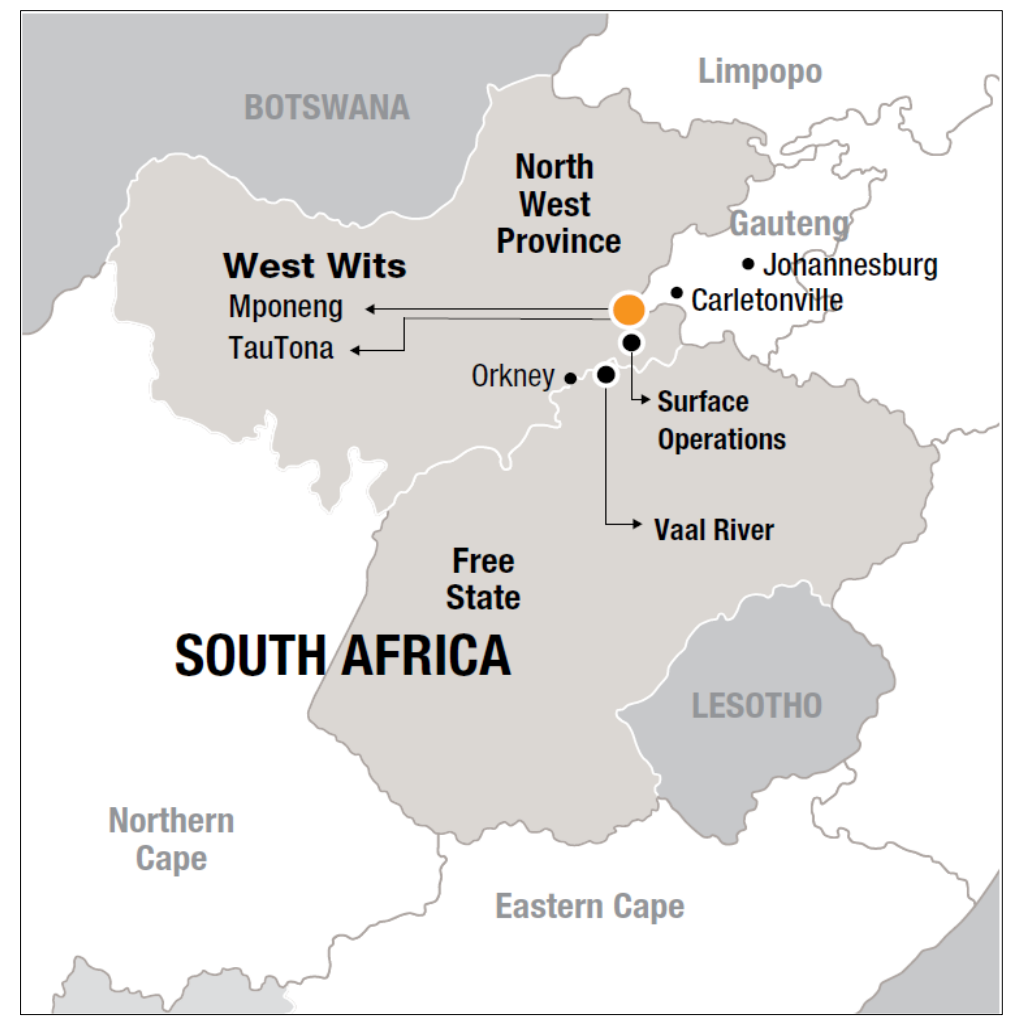

Figure 1. Location of Mponeng mine relative to major towns and cities

Following the work done by Scheepeers et al ( 2012), in corelating modelled stope closure to seismic response, strike stabilizing pillars were incorporated into the sequential grid mining layout with the intent of limiting stope closure and the corelating seismic response. The strike pillars where only established at the beginning of 2014 with the new mining layout taking full effect in 2016 when all mining raise lines had strike pillars. A reduction in the number of seismic events with magnitude $\geq 0.0$ was observed from 2016 (See Figure 2) with a significant drop in the annual seismic potency (See Figure 3). The reduction in production from 2013 did not result in a decrease in seismic potency until 2016. 


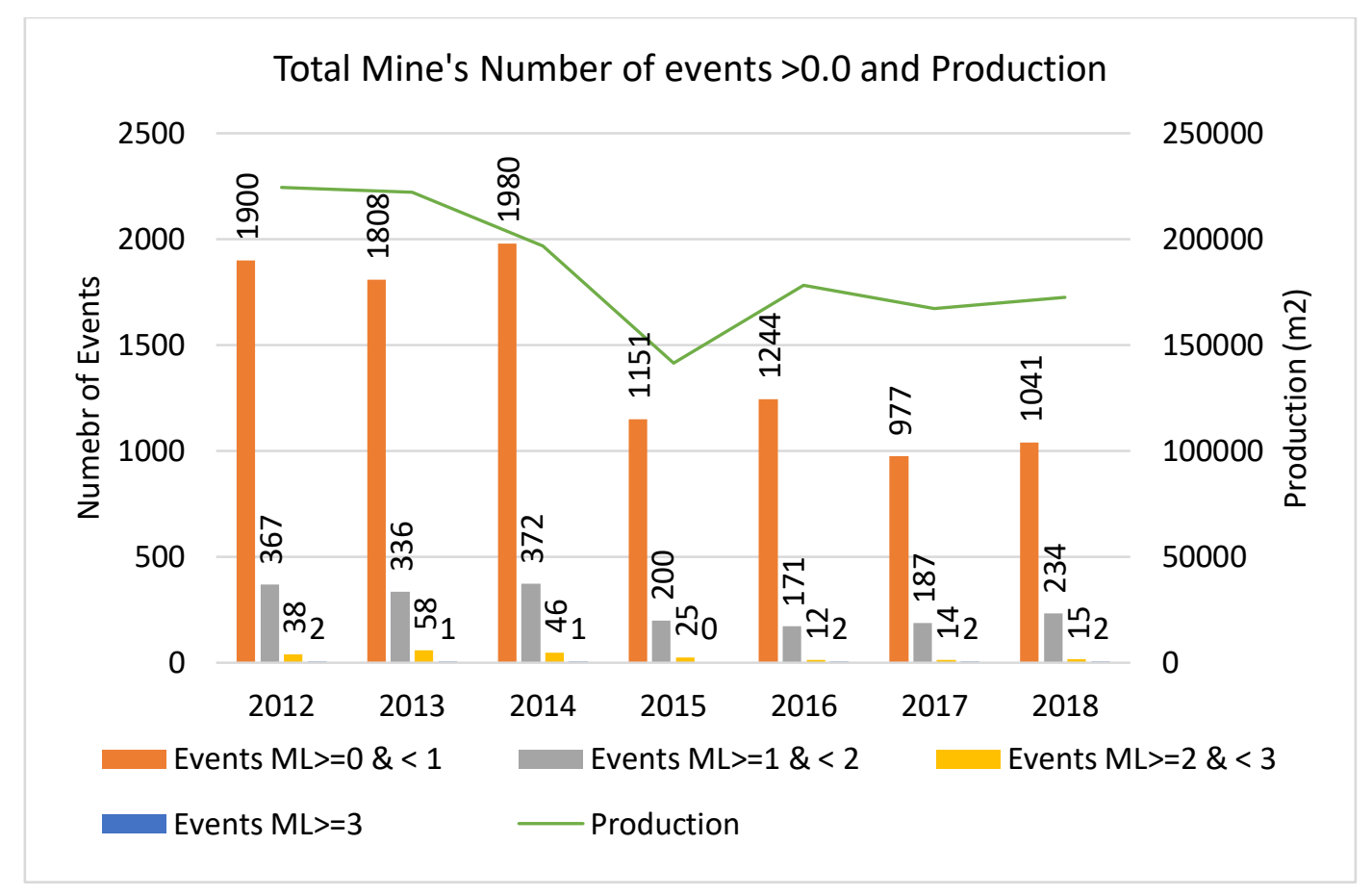

Figure 2. Total number of seismic events with magnitude $\geq 0.0$ per annum against mined area

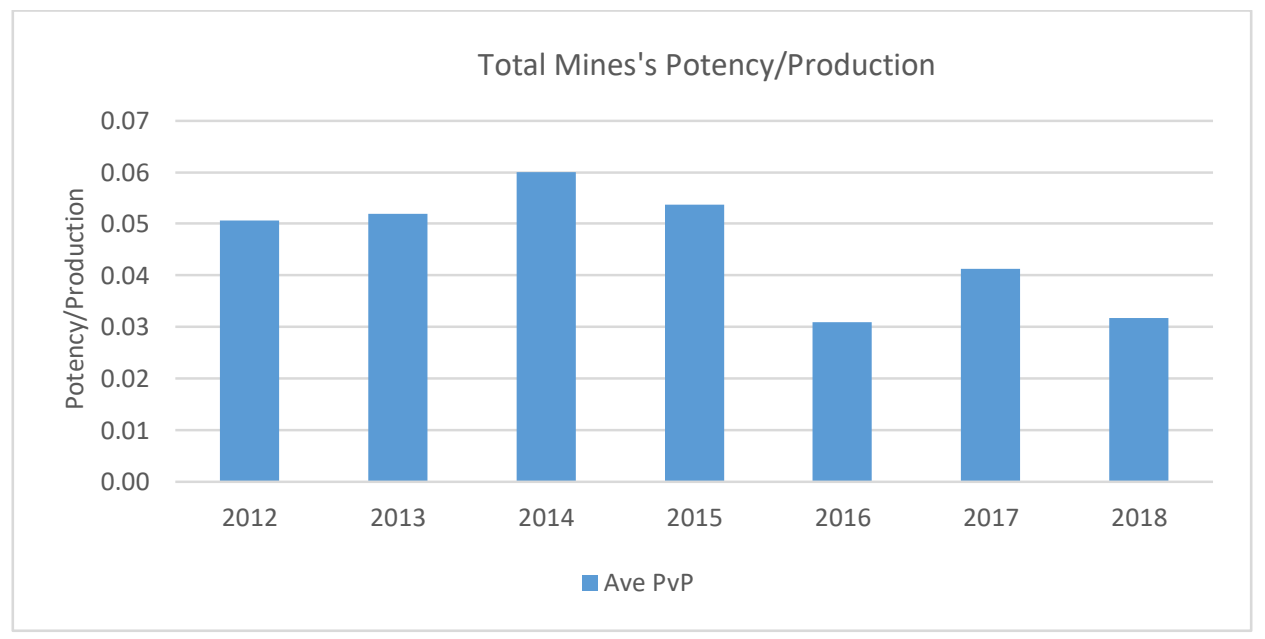

Figure 3. Annual seismic potency/production (area mined)

In 2016 the mining cycle was changed from two activities (support/breaking and cleaning) to three activities (breaking, clean and support). The three activities meant that the day shift crew was split into two smaller crews working in two panels in a single shift. One smaller crew drilling a supported panel and the other crew supporting a cleaned panel. This resulted in each panel being blasted every second day, preventing idle panels as opposed to the previous practice commonly referred to as roving where a crew was alternating between two panels once the maximum or minimum lead-lag is reached. The roving practice resulted in panels standing idle for at-list a period of 1-2 weeks. contributing significantly lead-lag standards non-compliance.

The new way of cycling between two or three panels has resulted in a significant improvement to adherence to the lead-lag standard. When looking at the seismic potency/production graph month on month it was observed that it fluctuated (See Figure 4) even though it was low annually. This implied that the seismic risk would be low in one month and high in the following month. 


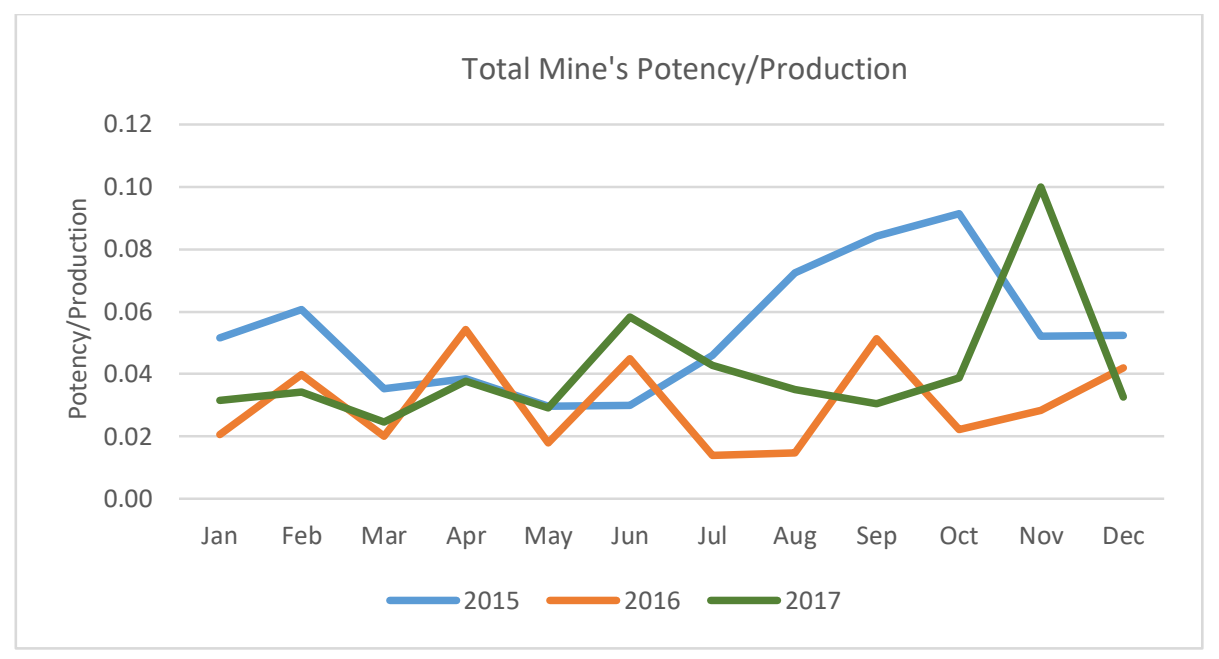

Figure 4. Monthly potency/production 2015 - 2017

It was found that most mining raise lines were established and maintained on the minimum end of the lead-lag standard. Maintaining minimum lead-lags highlighted a short coming in the mine's lead-lag standard of $5 \mathrm{~m}$ to $10 \mathrm{~m}$. The standard allowed for a $6 \mathrm{~m}$ variation in lead-lag in the same stope. The mine also allowed for a maximum panel length of $40 \mathrm{~m}$ measured from siding to siding without any specified minimum panel length. This allowed for big variations on panel lengths within the same stope. The variation of $6 \mathrm{~m}$ between lead-lags and variation in panels lengths resulted in non-ideal stope profile especially when majority of the lead-lags where kept a minimum. A non-ideal profile is defined as a profile that is not straight for the entire length of the stope or that is too flat (See Figure 5).

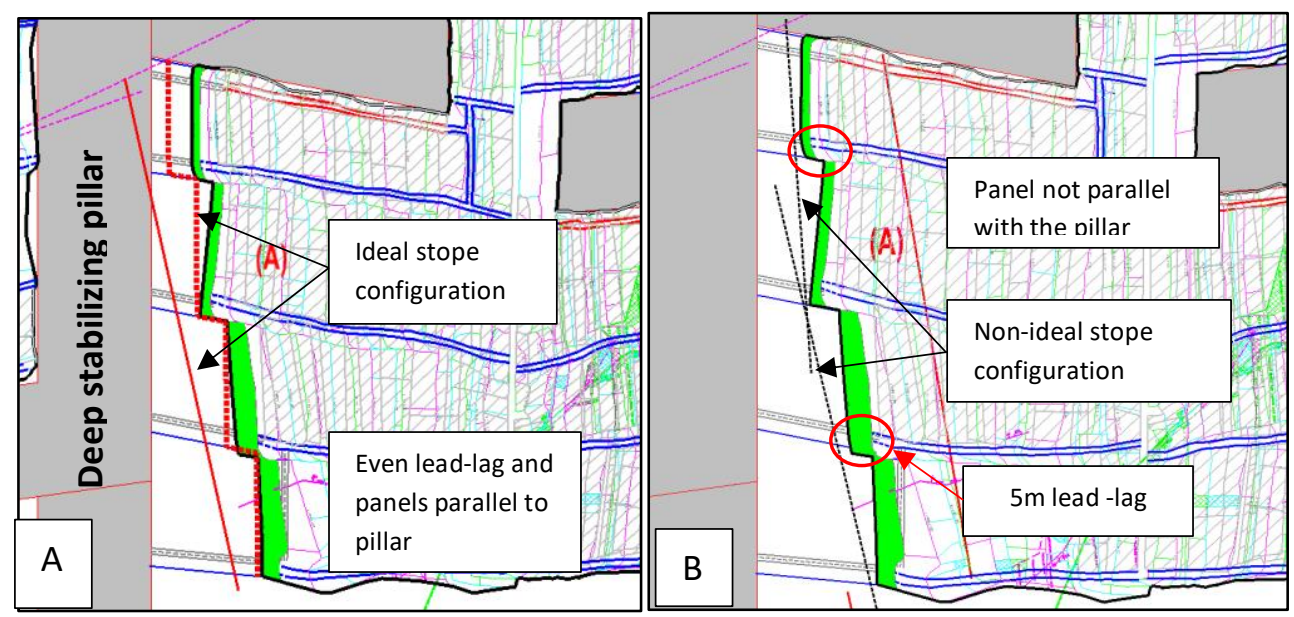

Figure 5a, Ideal stope configuration represented by the red dotted line and the red profile line, $b$. Non-ideal stope configuration represnted by the green filled face and the black dotted line

\section{MINING-INDUCED STOPE FRACTURES}

The inter-panel lead-lag is one of the major determinants of the overall stope profile. The stope profile in turn determines how the overall mining induced stress will be distributed around the mined-out area and the resultant nature of the fracturing occurring around the stope. This applies especially tor the mining induced shear fractures (See Figure 6) which form well ahead of the stope face and tend to conform to the broad orientations of the mining and not minor irregularities of the face or of small leadlags, Jager and Ryder (1999). These are similar type fractures referred to as the Type 2 fractures (See Figure 7), McGarr (1971), in which they are referred to as burst fractures. 


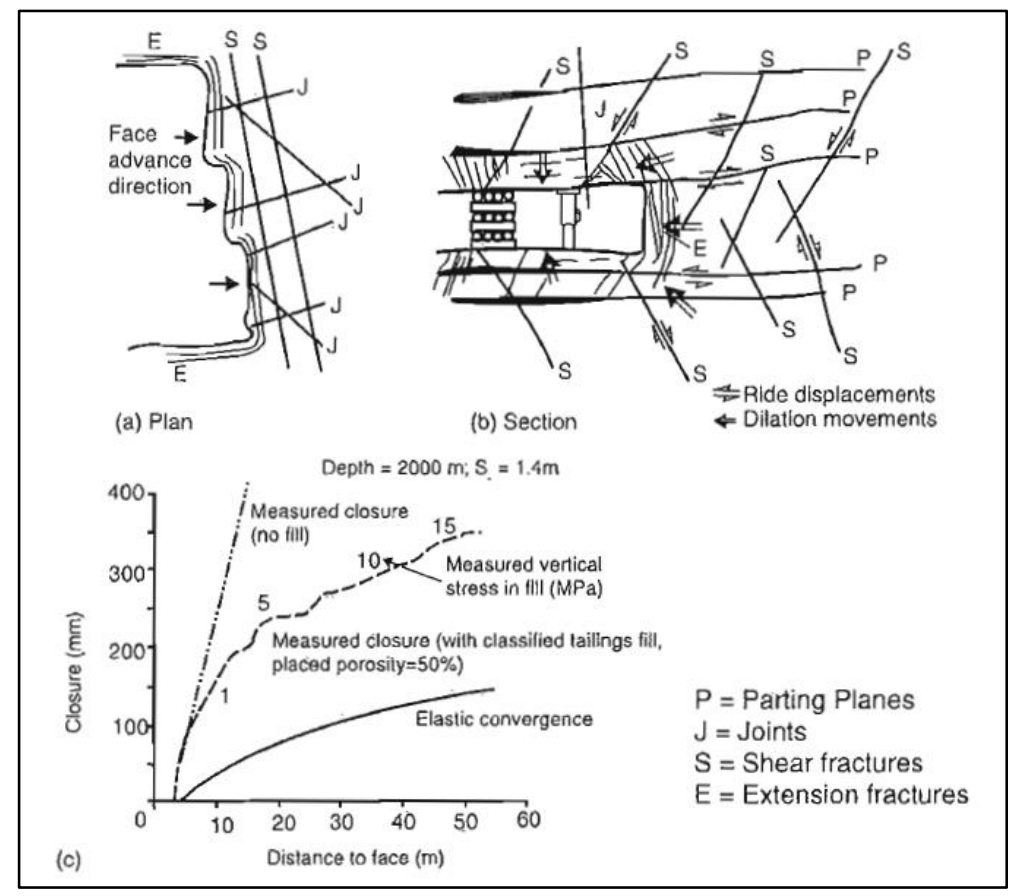

Figure 6. Fracture and deformation patterns around a deep stope, Jager and Ryder (1999)

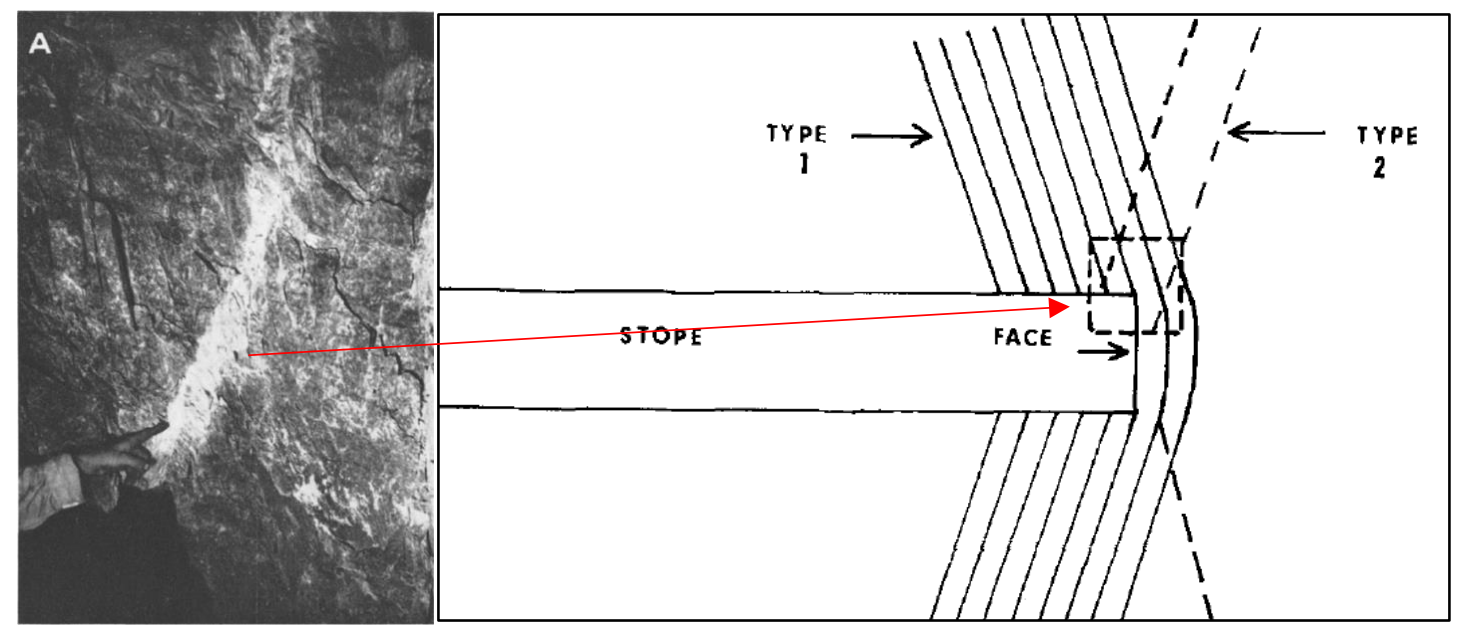

Figure 7a) Photograph of the Type 2 fracture dipping away from the face; $b$ ) Schematic indicating the Type 1 and Type 2 fractures and the position where the photo was taken, McGarr (1971).

By comparing the laboratory results on rock samples to that of the facture zones observed underground, McGarr et al (1979) proposed that the type 2 fracture starts as the stress increases within the rock and the microcracks which are near parallel to the major principal stress $\left(\sigma_{1)}\right.$ align to form a larger fracture that is orientated $30^{\circ}$ to $\sigma_{1}$. (See Figure 8) and some of these fractures are said to occur under dynamic conditions (Ortlepp shears) and are associated with larger magnitude seismic events, van Aswegen and Stander (2012). 


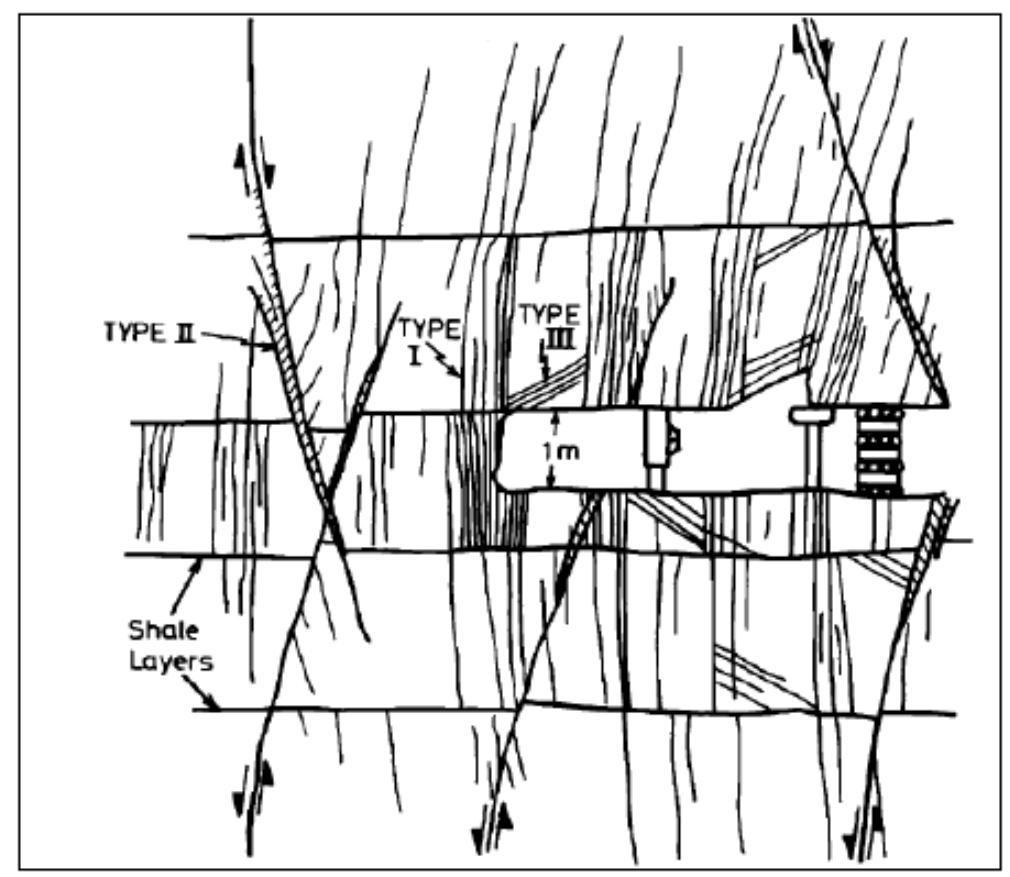

Figure 8. Distribution of fractures around a stope face. Their Type II were referred to as Ortlepp shears, Adams, Jager and Roering (1981)

\section{Influence of stope configuration on stress profile and shear fractures}

During the development of the sequential grid mining method, Applegate (1991) stated that the objective of the stabilizing pillars and controlled mining sequence was to reduce the face stresses and associated ERR), and to effectively bracket the geological discontinuities. He further added that reduced face stresses results in reduced seismicity and stress fracturing and therefore improved ground conditions and safety. One of the major concerns raised by Applegate (1991), was that poor face configurations could result in elevated ERR levels and increased seismicity.

It is however important to note that Applegate (1991), in his assessment, used a stope configuration with even length panels and a standard lead/lag of $10 \mathrm{~m}$ and did not give guidance on what defines a good configuration with respects to maximum and minimum panel length and lead-lags. If the type 2 fractures form in accordance to the overall stope profiles and not the individual lead/lags as explained by Jager and Ryder (1999); it can then be said that the lead/lags contributes significantly to the profiles of the type 2 fractures. Figure 8 indicates the same stope at $3400 \mathrm{~m}$ modelled with different profiles due to the different lead/lags. The stopes are configured with seven panels with varying panel lengths ranging from $25 \mathrm{~m}$ to $40 \mathrm{~m}$ with all panels being straight and parallel to the planned stopping position.

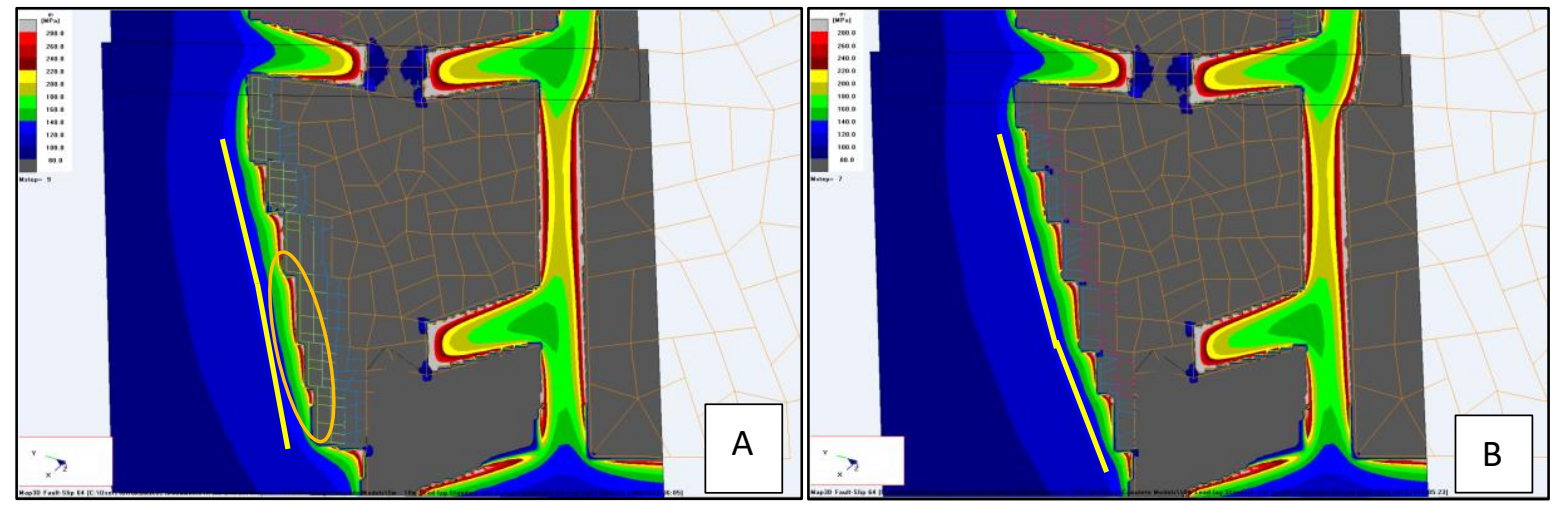

Figure 9a) Stope profile with varied panel lengths and varied lead/lags of 5-10 $m, b$ ) the same stope profile with varied panel lengths and fixed lead/lags of $10 \mathrm{~m}$ 
Work conducted in the SIMRAC project on lead-lag design criteria and seismicity patterns, Goldbach et al (2006), was aimed a quntifying the effects of lead-lags on fracturing, stability, support and seismicity. The project was successful in determining the influence of lead-lags on rock mass fracturing through the extensive fracture mapping that was conducted. The effect on seismicity was mainly confined to the seismic events directly linked to the lead-lag (See Figure 10) and not the regional seismic events linked to the mining profile or the type two fracture related events. The assessment showed that with lead-lags largger than $14 \mathrm{~m}$ the magnitude of the seismic event associated with the lead-lag increased to $>$ ML1.0.

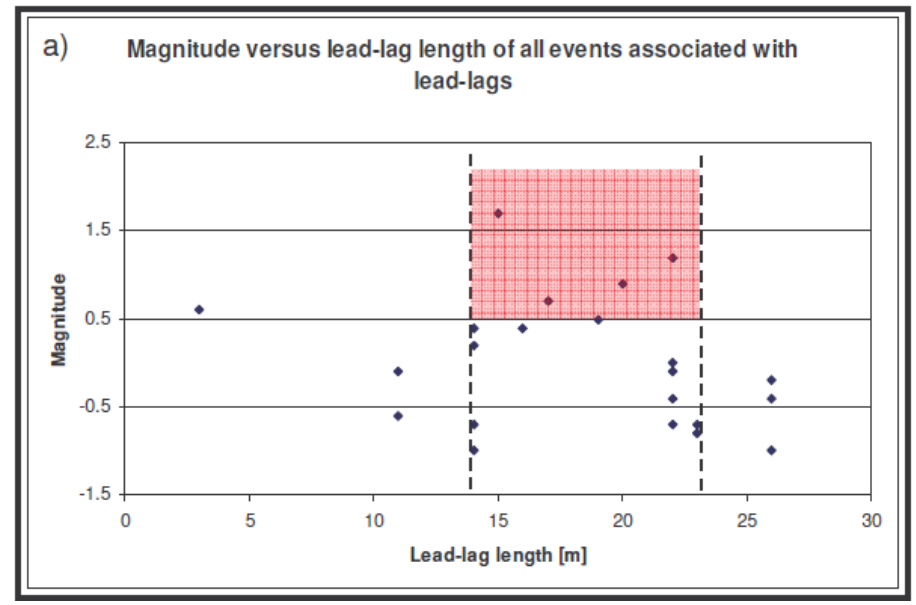

Figure 10. Seicmic event magnitude vs interpanel lead-lag, Goldbach et al (2006) (The fracture mapping indicated that the fracture density had a good variation of $0.2 \mathrm{~m}$ to $1.4 \mathrm{~m}$ between $7 \mathrm{~m}$ and $11 \mathrm{~m}$ inter-panel lead-lag (See Figure 11).

The SIMRAC project was concluded by recommending the following lead-lags for the different reefs to limit siding-parallel fracture extent of $3 m-5 m$

- $7.0 \mathrm{~m}-13.0 \mathrm{~m}$ for the Ventersdorp Contact Reef;

- $\quad 9.5 \mathrm{~m}-16.5 \mathrm{~m}$ for the Carbon Leader Reef;

- $4.0 \mathrm{~m}-9.0 \mathrm{~m}$ for the Vaal Reef; and

- $6.0 \mathrm{~m}-11.0 \mathrm{~m}$ for the Basal Reef.

An effective lead-lag is a function of the panel orientation, all the panels must be parallel to each other for the lead-lags to be effective.

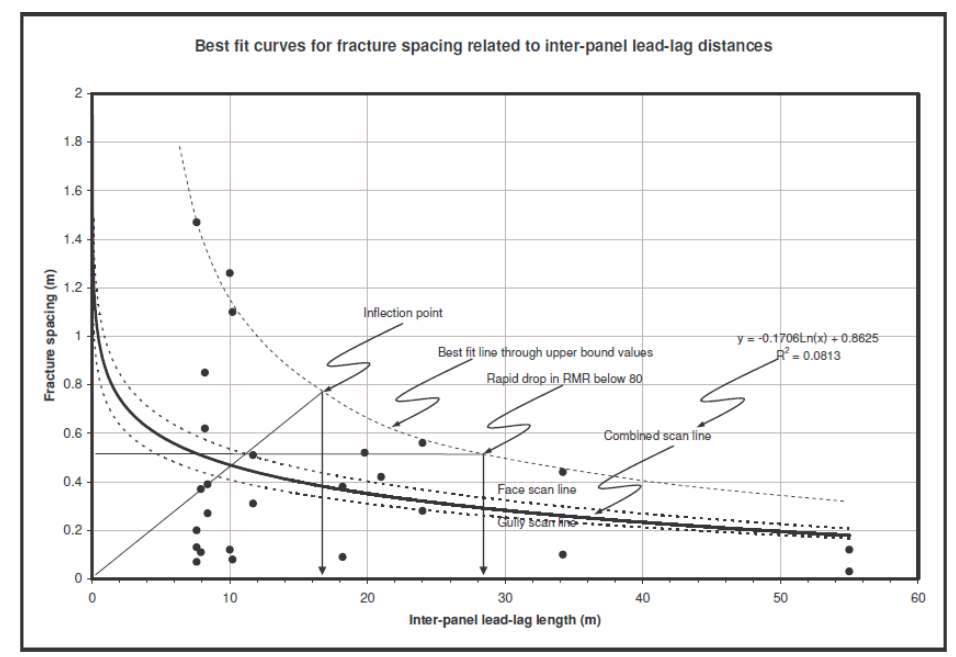

Figure 11. Best-fit lines of fracture spacing versus inter-panel lead-lag length for the gully, face and combined scan lines, Goldbach et al (2006) 


\section{Stress profile analysis ahead of a stope}

Numerical modelling results (See Figure 9), illustrates the effects of varied lead-lag and varied panel length in a stope. In Figure 8a, the red stress contour is continuous in the bottom left three panels as compared to Figure $8 \mathrm{~b}$, where the red stress contour is up intermittent. The resultant unbroken stress contours observed in Figure 8a would emulate a long-stressed abutment and this is due to the minimum lead-lag $(5 \mathrm{~m})$ and longer panel $(40 \mathrm{~m})$. The interaction of the bottom three panel creates a larger potential rupture plane (Type 2 fracture) compared to the intermittent stress contour in Figure $8 \mathrm{~b}$. In Figure 1Figure 11b it would be expected that the rapture plane would form as the individual fractures in each panel join-up, resulting a gradual release of strain energy ahead of the face.

In both configurations there is a distinct inflection point in the stress contours, with Figure 8a having a convex inflection point towards the solid, while Figure $8 \mathrm{~b}$ has a concave shape towards the solid. The inflection points in both configurations occurs at the longest panel in the stope. The one inflection point is at the top (See Figure 9a) while in Figure 9b it is at the bottom of the longer panel. Even though Figure $9 \mathrm{~b}$ had even $(10 \mathrm{~m})$ lead-lags, the $40 \mathrm{~m}$ long panel is still able to create an inflection point within the stope profile. The inflection point creates two different type 2 fracture patterns ahead of the stope. Figure 12 illustrates the stress profiles and the associated type 2 fractures indicated in solid black and yellow lines (A and B).

The concern created by the inflection point is that the formation of a type 2 fracture under dynamic conditions can result in the rupture plane extending (Fracture $\mathrm{C}$ indicated with a black dotted line in Figure 12) to the panels that are forming a different profile and fracture pattern. This can possibly lead to the brittle shear fracture along the rupture plane when extending into a different stope and fractur profile. Furthermore, this rupture plane (Fracture C) would occur much closure to the stope face of the panels in the different stope profile. The panel at the inflection point will be in the direct line of the rupture plane where the profile is convex towards the solid.

Further modelling of the lead-lag greater that $10 \mathrm{~m}$ indicated that the stress starts to concentrate at the corners of the panels when lead-lags are around $12 \mathrm{~m}$. This can create a highly stressed siding abutment (See Figure 13) which can result in burst type seismic events and highly fractured rock mass conditions.

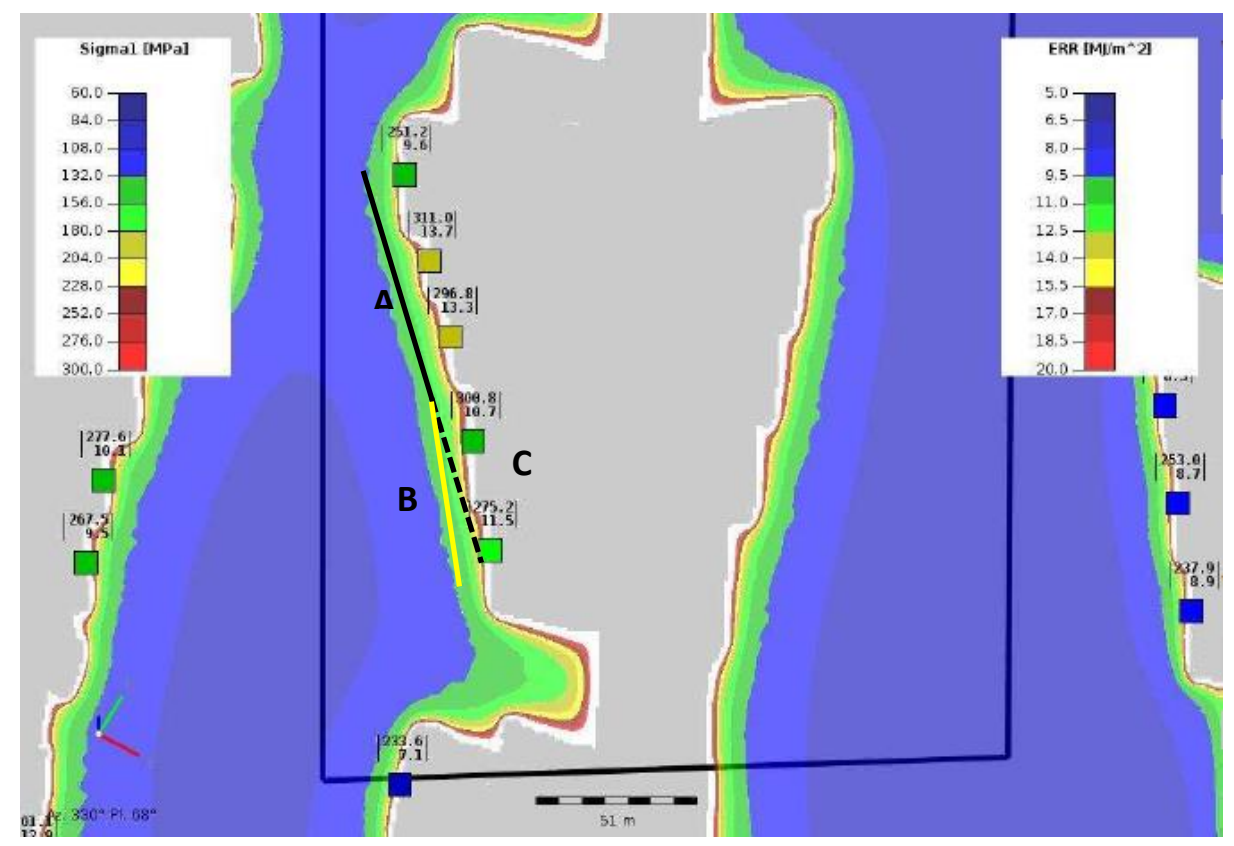

Figure 12. Stress Profile ahead of a stope a different profile and type 2 fracture forming ahead of the stope 


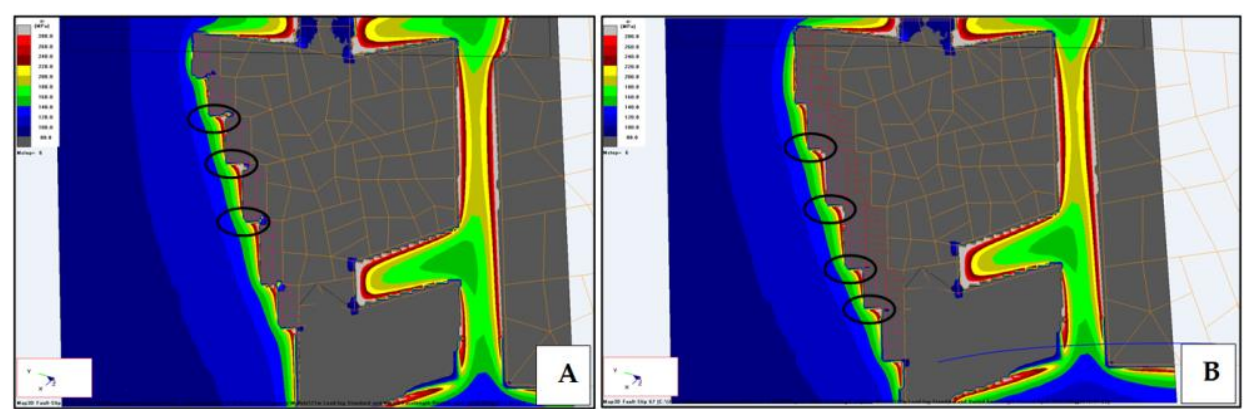

Figure 13a) Stope profile with varied panel lengths and lead/lags of $11 \mathrm{~m}, \mathrm{~b}$ ) the same stope profile with varied panel lengths and fixed lead/lags of $12 \mathrm{~m}$

\section{Seismic analysis of different stope profiles}

Seismic review of the raise line where stope profiles where compromised by either the variation in panel length and lead-lags or poor panel orientation showed that the seismic response was not uniform for the entire panel lenth. The 116-65 West stope had extreme panel length variation and maitained minimum lead-lags with one panel having an incorrect orientation (See Figure 14a). This resulted in two profiles being formed ahead of the stope with the bottom profile having a $10^{\circ}$ approach angle onto the dip pillar, while the top profile had $20^{\circ}$ approach angle. The top profile showed a high density of micro seismic events ( $<0.0$ magnitude) while the bottom profile had low density of micro seismic events (See Figure 14b). The same behaviour was observed at 116-35 East stope (See Figure15) where E7 panel did not form the same profile as the rest of the stope resulting in low a density of micro seismic events at E7 panel. The approach angle ahead of E7 was $<10^{\circ}$ while the bottom panels created a $17^{\circ}$ angle.

The micro seismicity is used as an indicator of released stored strain energy in the rock. High density micro seismic events translate to continuuos rock mass fracturing while low micro seismic activity indicates less fractuing and potential increase strain energy build-up. This can lead to a much more intact rock mass ahead of the stope which is conducive for sudden and violant rock mass failure or propagation of and brilltle shear fracture ahead of the stope.
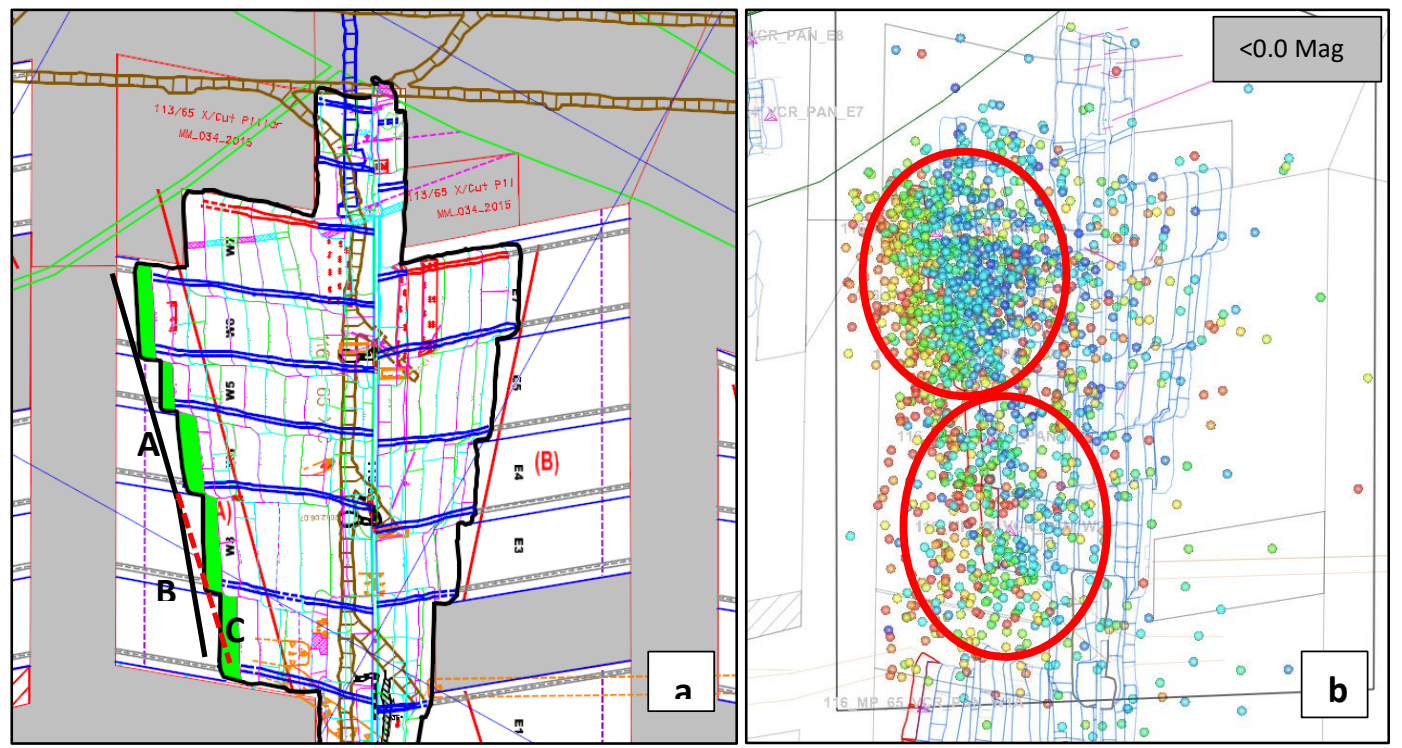

Figure 14a.116-65 West stope profile; $b$. Micro seismic events plot of the 116-65 raise line associated with the stope profile for 6 months 


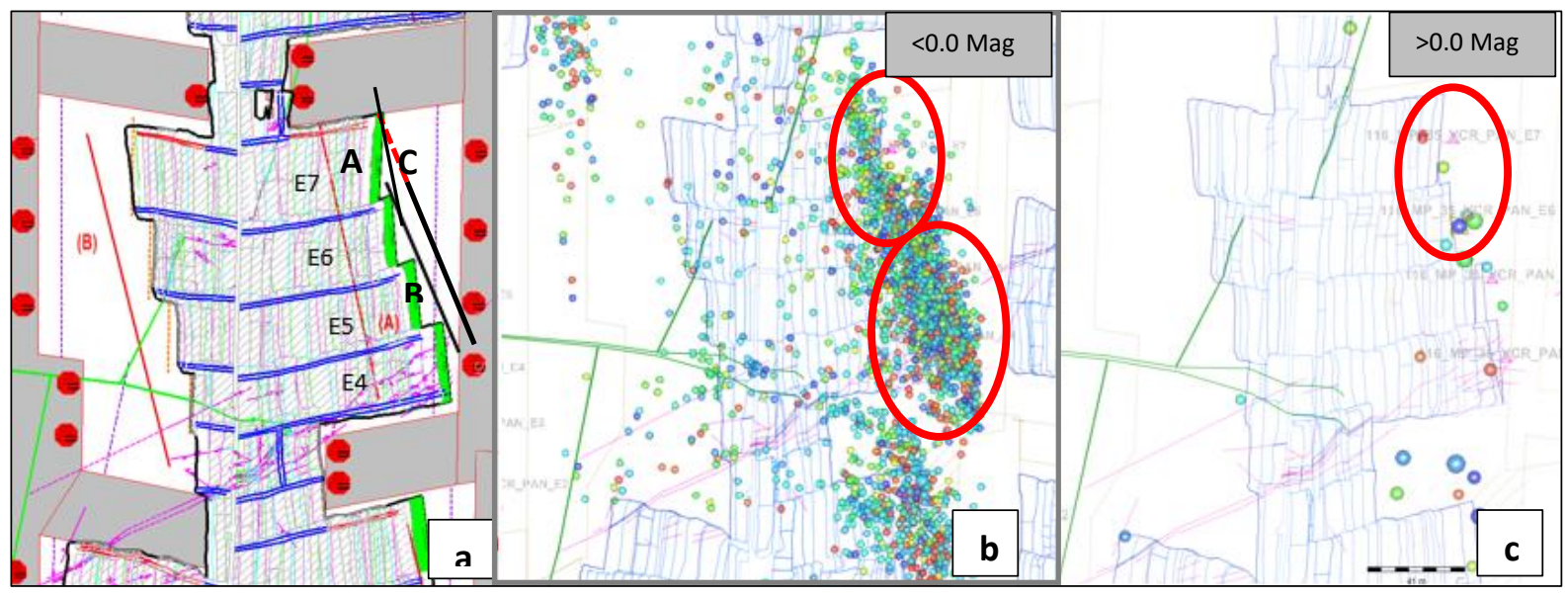

Figure 15a.113-35 Stope profile; $b$. Micro seismic events plot for 30 days; $c$. Event $\geq 0.5$ magnitude for 6 months

\section{DISCUSSION}

There is a good understanding in the fact that type 2 fractures (shear fractures) are the sources of the larger mining (face) related seismic events. Literature shows that the fractures are a function of the overall stope profile. The mechanism of fracture propagation is not clearly understood, however, McGarr et al (1979), attempt to explain their formation by comparing them to rock samples behaviour in the laboratory. By using this understanding, it is evident that the management of lead-lags plays an important role in controlling the development of the type 2 fractures and therefore reducing the associated seismic risk.

Through numerical modelling it was shown how the variation in lead-lag can result in unfavourable stress profiles ahead of the face and how extreme variation in panel length can cause inflection points in a profile. The work done in the SIMRAC project on lead-lags showed that lead-lag $<7 \mathrm{~m}$ and $\geq 12 \mathrm{~m}$ result in highly fractured panel sidings. Also lead-lag $>14 \mathrm{~m}$ result in seismic events with $>0.0$ magnitude along the sidings, Goldbach et al (2006). This correlated to the numerical modelling which showed that at lead-lags of $12 \mathrm{~m}$ high stresses starts to concentrate along the sidings which will also lead to increased fracturing. Profiles with low angle $\left(\leq 10^{\circ}\right)$ of approach can result in a low occurrence of micro seismic events and an increase in stored strain energy. The lack of fracturing in the rock mass can lead to the dynamic formation of the shear fractures ahead of the stope face.

\section{Development of the ideal stope profile at Mponeng}

Table I indicates the different approach angles created ahead of the face by the different panel length and lead-lag combinations. The combinations that result in angles $\leq 12^{\circ}$ are red to prevent flat profiles. Visual analysis of the stope profiles showed that the change of the angle of approach became more profound at around $7^{\circ}$, and it was therefore decided to limit the approach angle variance to $5^{\circ}$. Table I shows that the smaller panel length results in significant changes in approach angle with a change in lead-lag. Time and workload studies conducted at Mponeng showed that to achieve optimal and efficient production, the panel length must be maintained between $30 \mathrm{~m}$ and $35 \mathrm{~m}$. 
Table I. Approach angles formed by different panel lengths and lead-lags combinations

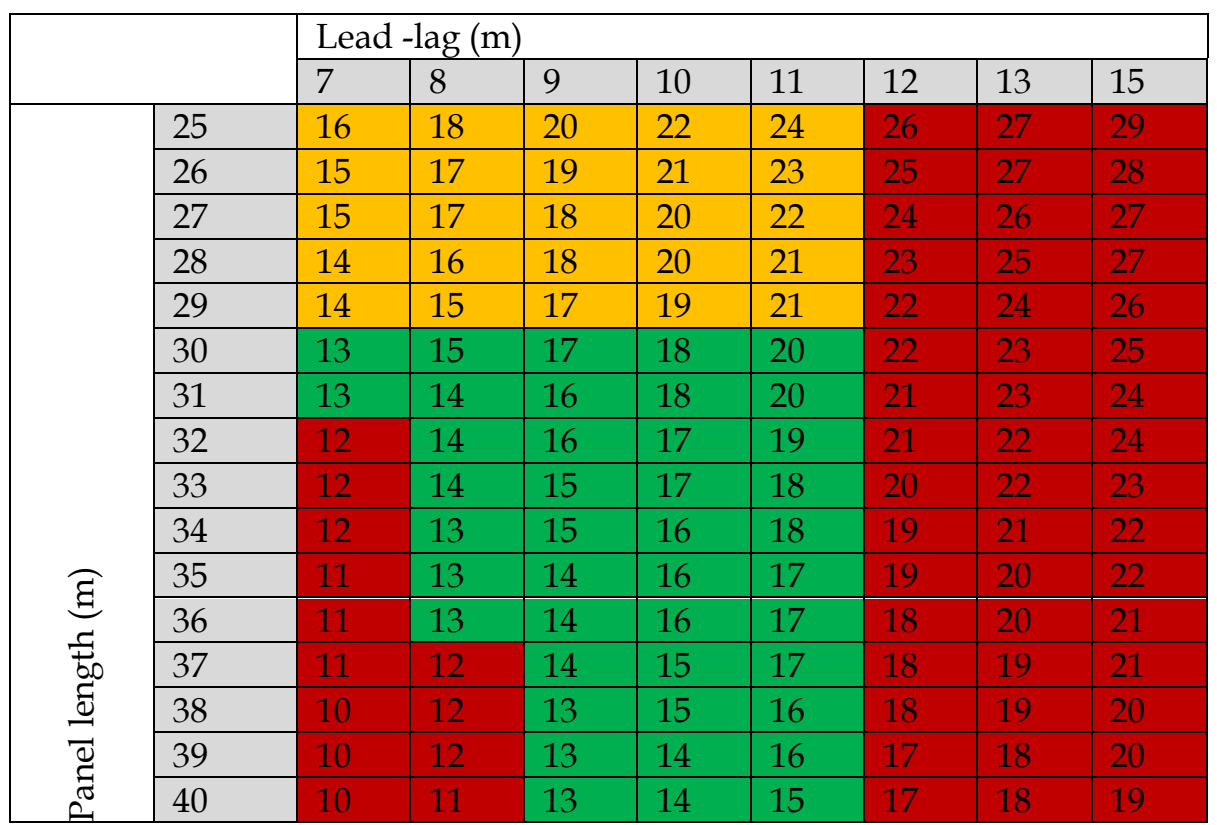

To achieve an ideal stope profile to manage the seismic risk associated with the formation of the shear fractures under dynamic conditions while also not introducing strata control challenges, the profile must ensure the following:

- A uniform profile ahead of the stope by ensuring minimal approach angle change $\left(\leq 5^{\circ}\right)$,

- an approach angle $>12^{\circ}$ must be maintained always;

- lead-lag must not be less than $7 \mathrm{~m}$ or greater than $12 \mathrm{~m}$ to prevent stressed abutments/siding and increased fracturing, Goldbach et al (2006);

- the panel length variations within a stope to be maintained to a maximum of $10 \mathrm{~m}$. That is the difference between the shortest and the longest panel in a stope must not be more than $10 \mathrm{~m}$. Example: if the shortest panel is $25 \mathrm{~m}$ (minimum) then the longest panel will be $35 \mathrm{~m}$ (maximum); and

- panel lengths not to exceed $40 \mathrm{~m}$ and should not be less than $28 \mathrm{~m}$ to manage changes in the approach angle and enable efficient production.

In December 2017 the revised stope profile strategy was implemented at Mponeng mine, where the lead-lag standard was limited to $7 \mathrm{~m}-11 \mathrm{~m}$ and new stope layouts were revised to ensure panel lengths of between $30 \mathrm{~m}-35 \mathrm{~m}$. In stopes which were established with longer panels $(>35 \mathrm{~m})$ and very short panels $(<25 \mathrm{~m})$, special lead-lag were put in place. All panel orientations were corrected to ensure all panels were close to parallel within the same stope.

\section{RESULTS}

Figure 16 indicates the monthly compliance tracking of the parameters that ensures the correct stope profiles are established and maintained. Although only an average of $60 \%$ compliance was achieved for 2018, the overall mine's stope profiles improved to close to ideal. Referring to Figure 2, the same production volume was achieved between 2015 and 2018, however, the highest number of $\geq 1.0$ magnitude events were recorded in 2018. Importantly when looking at Figure 17, the potency/production graph for 2018 is the most constant of all the four graphs. The 2018 graph is contained between 0.02 and 0.04, except for May and December, when $>3.0$ magnitude evets occurred along geological structures in the back areas. 


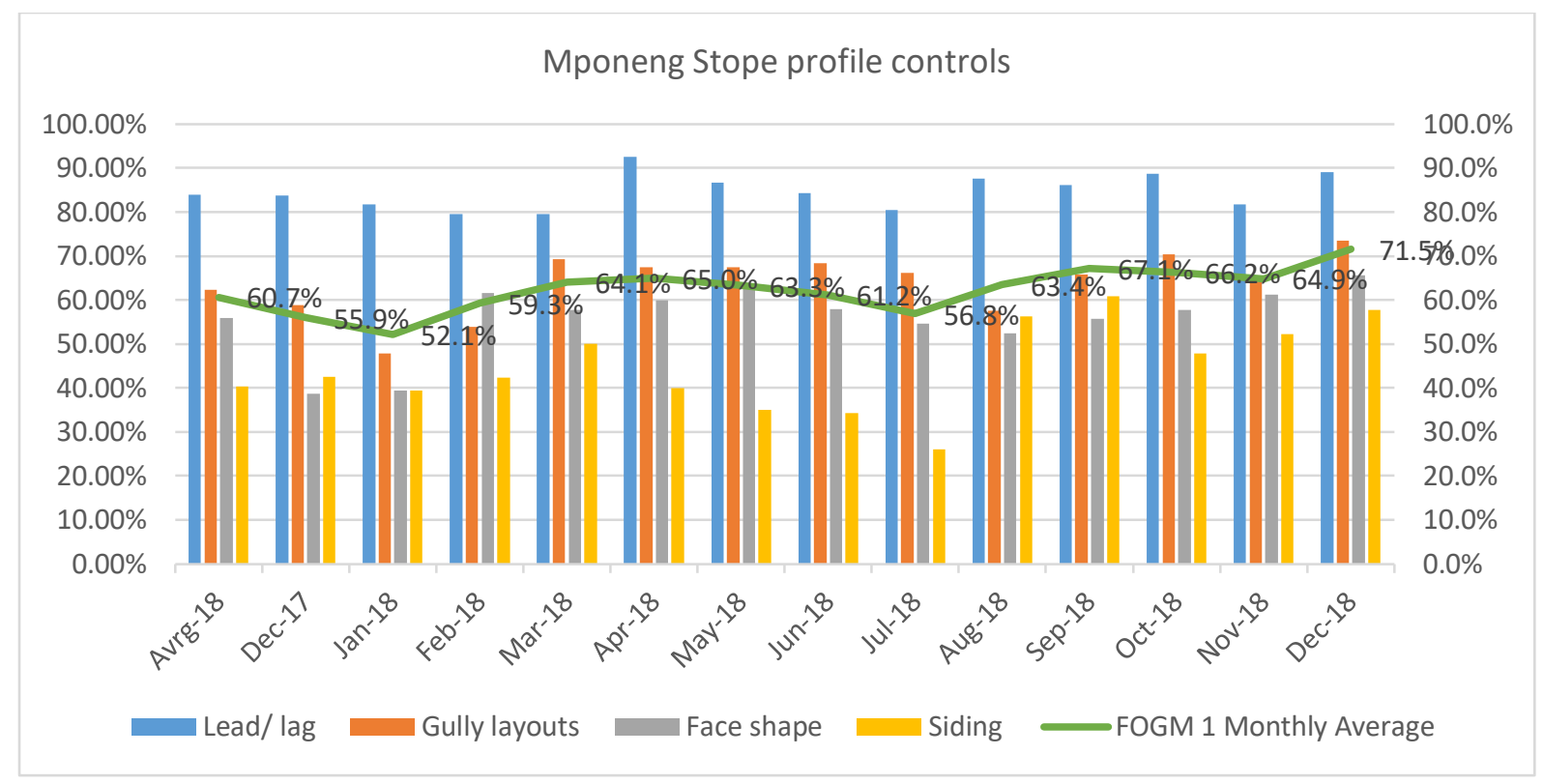

Figure 16. Compliance with stope profile parameters

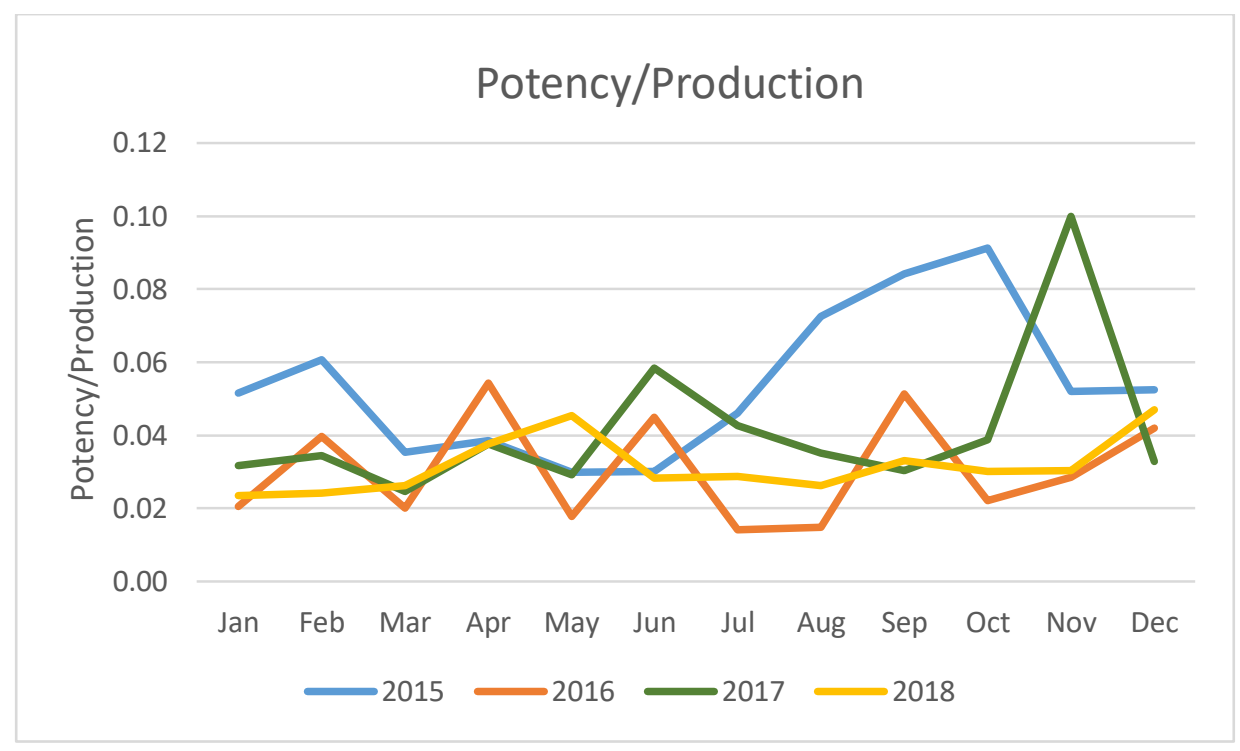

Figure 17. Monthly potency/production 2015 - 2018

\section{CONCLUSION AND RECOMMENDATIONS}

By implementing an ideal stope profile aimed at managing stress distribution ahead of the stope and the associated seismic events, a more consistent seismic profile was achieved in 2018 when compared to the previous years.

Significant differences in the panel lengths within the stope matched with insufficient lead-lag standards can result in different stress profiles within the stope causing different seismic clusters and erratic seismic patterns,

Although a constant seismic pattern was achieved, further analysis of the seismic events with $\geq 1.0$ magnitude associated with the stope face must be conducted. This will focus on events occurring ahead of the stope associated with rock mass fracturing. Seismic moment tensors can be used to establish the source mechanism. 


\section{REFERENCES}

Adams, G. R., Jager, A. J., \& Roering, C. (1981). Investigations of rock fractures around deep level gold mine stopes. Proceedings of the 22nd US Symposium on Rock Mechanics, (pp. 227-236). Cambridge, Massachusetts: American Rock Mechanics Association.

Applegate, J. D. (1991). Rock Mechanics Aspects of Sequential Grid Mining. Johannesburg: University of the Witwatersrand.

Goldbach, O. D., Rangasamy, T., Linzer, L. M., Kataka, ,. M., Spottiswoode, S. M., \& du Pisani, P. (2006). Lead-lag design criteria and seismicity patterns. Johannesburg: SIMREC.

Jager, A. J., \& Ryder, J. A. (1999). A hand book on rock engineering practice for tabular hard rock mines. Johannesburg: SIMRAC.

McGarr, A. (1971). Violent Deformation of Rock Near Deep-Level, Tabular Excavations - Seismic Events. Bulletin of the Seismological Society of America, 1453 - 1466.

McGarr, A., Pollard, D., Gay, N. C., \& Ortlepp, W. D. (1979). Observations and analysis of structures in exhumed mine-induced faults. Observations and analysis of structures in exhumed mine-induced faults. 79-1239, $101-120$.

Ryder, J. A., \& Jager, A. J. (2002). A Textbook on Rock Mechanics for Tabular Hard Rock Mines. Johannesburg: The Safety in Mines Research Advisory Committee (SIMRAC).

Scheepeers, L. J., Hofmann, G., \& Morkel, I. G. (2012). The Study of Seismic Response to Production for a Grid Mining Layout. Southern Hemisphere International Rock Mechanics Symposium. Sun City: SAIMM.

Van Aswegen, G. (2013). Forensic rock mechanics, Ortlepp shears and other mining induced structures. Eight international symposium on Rockburst and Seismicity in Mines, Volume 1, (pp. 1-19). SaintPetersburg.

van Aswegen, G., \& Stander, M. (2012). Origins of some fractures around tabular stopes in deep South African mines. The Journal of The Southern African Institute of Mining and Metallurgy, 729 - 735. 


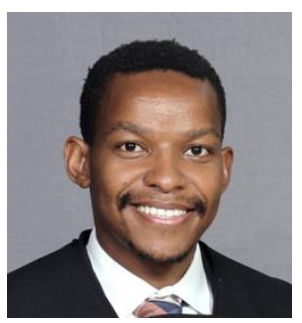

\section{Obakeng Rakumakoe}

Rock Engineering Manager

Anglogold Ashanti

He started his professional career in 2008 at Ukhozi Project Management as a graduate working on operational improvement using Theory of Constraints (TOC) philosophy. Later in the same year joined Anglogold Ashanti (AGA) South African operations as a Management trainee in their rock engineering department. Between August 2008 and June 2011, spend time at Savuka, Mponeng and Great Noligwa mines respectively until appointed as a Senior Rock Engineering Officer (SREO) at Mponeng mine in August 2009. As a SREO at Mponeng mine got to work on the different rock engineering aspects on an operating deep gold mine including operational and production rock engineering, brown fields projects (deepening prefeasibility and feasibility studies) and continues research and development. In October 2014 was promoted to a position of Rock Engineering Manager for Mponeng mine, which position he retains at present. 